\title{
Students' Blogs as a Tool for Learning Clinical Biochemistry
}

Cubas, E. ${ }^{(1)}$; Oliveira, J. ${ }^{(1,2)}$; Lobo, F. ${ }^{(1)}$; Mesquita, D.M. ${ }^{(1)}$; Hermes-Lima, M. ${ }^{(2)}$

${ }^{(1)}$ Fac. Medicina, ${ }^{(2)}$ Depto. Biologia Celular, Universidade de Brasília (UnB).

In the past decade, there has been an exponential growth of blogs on biomedical subjects with reliable contents. The potential use of this media as a learning tool has been recently tried in a medical residence at Harvard University, where students had to produce blogs as part of their duties. At Brasília University, a similar experience was tested with freshmen medical and nutrition students taking Basic Biochemistry $(\mathrm{BB})$ with the goal of producing blogs on clinical biochemistry (CB) topics. In the last 4 teachingsemesters, students' acceptance ( $n=267$ students) regarding BB-blogs was evaluated through 6-point Likert questionnaires. $84 \%$ of them agreed that the preparation of their blogs was enjoyable and positive for their academic formation (they marked 4 to 6 in the questionnaire). $57 \%$ of students (those marking 5-6) believed that the elaboration of blogs boosted their interest for BB/CB. For $56 \%$ of students (those marking $5-6$ ), the blogs motivated them to look for extra-class articles on CB. Only $13 \%$ of students (those marking 1-3) did not agree that these blogs are relevant learning tools. 38 out of 58 students' BB-blogs scored 9.0 or above, only 3 scored below 7.9 (out of 10). These results suggest that student blogs have potential to be effective in stimulating $C B$ learning. Support: CNPq. Keywords: Medical education, Internet, Active learning. 